\title{
El secreto bancario frente a la Administración Tributaria
}

\author{
Leal Wilhelm, Salvador*- \\ * Profesor de Derecho Constitucional y de Procedimientos Contencioso Administrativos \\ de la Facultad de Ciencias Jurídicas y Políticas de La Universidad del Zulia. Miembro del \\ Programa de Promoción a la Investigación (PPI), Nivel II. Doctor en Derecho. Dirección \\ Institucional y de correspondencia: Núcleo Humanístico de LUZ. Escuela de Derecho. \\ Departamento de Derecho Público. E-mail: slealw@luz.edu.ve
}

\section{Resumen}

El propósito de este estudio es realizar un análisis jurídico del secreto bancario desde el punto de vista del constitucionalismo, partiendo de la consideración del mismo como una faceta del derecho fundamental a la intimidad. Pero, en el entendido de que todo derecho es limitable o relativo, aun los derechos constitucionales. La metodología empleada es el análisis de la normativa legal que contempla o limita el derecho bancario. Se concluy ó que el secreto bancario está incluido en el derecho a reservarse la información, que aisladamente carece de significado pero puede arrojar un precipitado que la persona puede decidir conservar para sí o revelar. Esto es necesario pues esa información puede traer consecuencias negativas sobre el particular. Por otra parte, el secreto bancario sin duda es necesario para proteger informaciones personales anejas a las patrimoniales. Ese derecho al secreto bancario puede limitarse en razón del deber de contribuir con el sostenimiento de las cargas publicas. La vigilancia de su cumplimiento exige que el Estado tenga acceso a la información en poder del banco, de forma limitada esto es, sólo individualizada y exclusivamente a la información con trascendencia tributaria, básicamente: ingresos. Entonces, la limitación del derecho deberá respetar su contenido esencial debiendo ser además razonable y necesaria.

Palabras clave: Secreto Bancario, Tributos, Intimidad, Administración Tributaria.

\section{The Banking Secret Versus the Tributary Administration}

\author{
Abstract \\ The purpose of this study is to undertake a juridic analysis of bank privacy from the \\ constitutional point of view, considering the same as a fundamental facet of legal privacy. \\ However, since all rights have limitations and are relative, even constitutional laws, this is
}


understood. The methodology employed was normative legal analysis that contemplates or limits banking rights. The conclusion is that banking secrecy is included in the right to reserve information, which in isolation has no significance, but which could shed light on activities that a person may want to remain private, o reveal as the case may be. Also, the bank secret without doubt is necessary in order to protect personal information apart from patrimonial information. This banking secret right could be limited when it is related to a person who is in public office. The surveillance of public officials could justify access to information in a limited form only and exclusively in relation to tax information, basically income. This basic rights limitation should respect the essential content of the law as well as be reasonable and necessary.

Key words: Bank secret (privacy), taxes, privacy, tax administration.

Recibido: 04-05-10. Aceptado: 04-11-15

\section{Introducción}

El artículo 251 del Decreto con Rango y Fuerza de Ley de Reforma de la Ley General de Bancos y otras Instituciones Financieras (Presidencia de la República, 2001a) establece la obligación, para las instituciones financieras y otras personas sometidas a su control, de suministrar información a la Superintendencia de Bancos (Sudeban). La ley no específica qué tipo de información. A los efectos de que ésta ejerza su función regulatoria del sistema financiero bancario nacional. El artículo 252 ejusdem (Presidencia de la República, 2001a) establece la no oponibilidad del secreto bancario, profesional o confidencialidad alguna a la Sudeban. En ejercicio de esta competencia regulatoria, Sudeban inició el Proyecto ROCA para: “... proveer a la Superintendencia de un Sistema de Información Integral Automatizado que contribuya con el ejercicio de una eficaz supervisión basada en el riesgo" (Sudeban, 2004a).

El Proyecto se paraliza cuando los bancos, alegando el secreto bancario, se oponen al envío de la información (Sudeban, 2004 b). I gual respuesta obtuvo el Servicio Nacional Integrado de Administración Tributaria (SENIAT) frente a pedidos similares (Rodríguez, 2004: A-18). Ante todo esto cabe preguntarse: ¿Son competentes Sudeban y el Seniat para solicitar la información? El secreto bancario, ¿puede ser opuesto a los órganos o entes del Estado en cumplimiento de funciones que les son propias? Si el secreto bancario tiene fundamento constitucional, ¿es absoluto?. Por medio del análisis sistemático del ordenamiento constitucional y legal vigente, con apoyo en la normativa comparada, se establecerá si la postura de los bancos frente al Estado, se ajusta a Derecho. 


\section{El Estado y la provisión de bienes públicos}

En su Tratado de la Naturaleza Humana, David Hume (1740:741) justifica la existencia del Estado como una solución a la existencia de externalidades. Si un fundo es afectado por inundaciones, el dueño proveerá auxilio por su propio interés. Si la inundación afecta a dos vecinos, ambos negociarán una solución. Pero, si mil personas son afectadas no habrá solución consensual. Dado que, todos saben que el interés de cada uno es impedir las inundaciones y que cada uno estará dispuesto a hacerlo, con esto los demás ganarán aún sin participar en la solución, entonces, nadie hará nada. Pero pueden ponerse de acuerdo en nombrar a un tercero para que lo haga y coactivamente obtenga los recursos de todos los beneficiarios. La protección contra inundaciones es un tipo de bien público.

Son bienes públicos aquellos que la sociedad desea consumir y que, una vez provistos, no pueden ser negados a ningún miembro de la sociedad, tales como la seguridad y defensa contra ataques exteriores, combate del delito o administración de justicia. Cuando se detiene, enjuicia y envía a la cárcel a un delincuente todos los ciudadanos obtienen tranquilidad, no solo a quien fue robado. Luego es injusto que no todos colaboren en la provisión del bien.

Quienes rechazan la provisión de información al Seniat y Sudeban se beneficiarán con la provisión de bienes públicos por el Estado. El Estado provee el marco institucional que el mercado requiere pues: el mercando es limitado por costos de transacción derivados de información incompleta, incompleta definición y garantía de los derechos de propiedad... Las instituciones ayudan a gerenciar los riesgos derivados del intercambio comercial, aumentando eficiencia y aumentando las ganancias (Banco Mundial, 2002:5).

Y obviamente, el crear y mantener las instituciones exige recursos monetarios. Los Estados obtienen sus recursos de muchas maneras. Pero, impuestos y deuda, los medios fiscales, son los más convenientes y abundantes.

Mientras el Estado se limitaba a ser un "vigilante nocturno" sus requerimientos de ingresos eran pocos. En todo caso, su poca tecnificación y organización le impedía obtener ingresos que no fuesen fáciles de recaudar. Las fuentes principales eran impuestos como el de capitación, un monto fijo por hombre adulto o bien impuestos sobre el comercio, los primeros evitaban una "intolerable pesquisa" sobre la fortuna personal (Smith, 1776: 766) Y los segundos se realizan sobre "operaciones visibles y fáciles de someter a tributación" (Banco Mundial, 2002: 110). 
Pero al avanzar el siglo XIX la franquicia electoral va aumentando y el Estado Moderno, imitando al gran proveedor que dio origen al Estado antropológicamente hablando (Harris, 1985: 76), decidió comprar la fidelidad de los nuevos votantes. Legitimarse por medio de la multiplicación de las prestaciones. Surge entonces, el Estado Social que busca “liberar de la necesidad" y garantiza libertades positivas. Que se pretende, satisfagan esas necesidades que crecen con el número de votantes y que se hacen cada vez más complejas y costosas, a medida que las necesidades más básicas son satisfechas. Cuando todos tienen instrucción primaria, se exige la secundaria y eventualmente la universitaria, y todo a cargo de los recursos del Estado (Stigler, 1970: 107).

Mayores recursos exigieron mayores ingresos. En el siglo $\mathrm{XIX}$ y a principios del $\mathrm{XX}$, se popularizó como medio de obtener ingresos, el impuesto sobre la renta, que pecha todos los ingresos, excepto aquel que se produzca por sucesión, que excedan a un límite llamado exención de base que se traduce en un mínimo vital que permite excluir del impuesto a aquellos que no aportarán dinero suficiente para cubrir los costos de recolección. Y dan un efecto redistributivo al impuesto sobre la renta.

Pero, determinar el ingreso real no puede hacerse: Sin una pesquisa más intolerable que la requerida por cualquier clase de impuesto y que se renueve por lo menos cada año, sólo se basaría en indicios o conjeturas. El reparto del gravamen dependerá en la mayor parte de los casos, del buen o mal humor de los exactores haciéndose absolutamente arbitrario e incierto (Smith, 1777: 766).

Por otra parte, al multiplicarse el número de contribuyentes y tomando en cuenta la complejidad que en muchos casos puede tener la base imponible, se exigiría el empleo de recursos excesivos por parte del estado para recaudarlos. Eventualmente, se emplearían mas recursos para recaudar los tributos que los que se obtendrían por esa labor.

En consecuencia, el Estado delega la labor de determinar, liquidar e ingresar el impuesto en manos del propio contribuyente. Se establece un sistema basado en el "cumplimiento voluntario" (Morgan, 1999: 2). El sistema parte de la buena fe de los contribuyentes y está diseñado: Para lograr el objetivo propuesto en la generalidad de los casos y no para cubrir las posibles excepciones al comportamiento normal del ciudadano (Presidencia de la República, 1999: 90). Se considera entonces excepcional el incumplimiento. Y se sujeta a sanciones al ciudadano que no cumple con declarar o ingresar el tributo.

Dado el carácter intrusivo y lo antieconómico de la labor de recaudación hecha por los 
órganos y entes administrativos, se establece un sistema que se basa en la autoliquidación que es el resultado de: Aquel deber jurídico sensu stricto, establecido por ley a cargo de un particular legitimado y consistente en la realización de todas aquellas operaciones de interpretación, valoración y cálculo necesarias para la cuantificación de la obligación tributaria derivada de los hechos imponibles declarados por él mismo (Fernández, 1995: 27).

El contribuyente posee la información necesaria para realizar la determinación tributaria por lo que le resulta más fácil hacerla. Al mismo tiempo, la autoliquidación le permite conservar privada la información, si bien deberá poner a disposición algunos documentos que eventualmente pueden poner en riesgo su intimidad tales como los recibos de pagos que justifican los desgravámenes (Asamblea Nacional (A. N), 2001a: Arts. 92 y 97).

Pero, al mismo tiempo se le está imponiendo una tarea material e intelectual importante. Elaborar la declaración de rentas no se limita a llenar un formulario. Es necesario interpretar la ley y aplicarla. Realizar operaciones contables y aritméticas. Luego de llenar el formulario según el monto retenido y el monto a pagar debe enterarse en un banco. Todo esto requiere además de cierta capacidad intelectual, de tiempo. En definitiva, es una carga que la ley autoriza a establecer mediante resolución del Ministerio de Finanzas (A. N , 2001a: Art. 85)

La Constitución de la República Bolivariana de Venezuela (CRBV) establece la obligación de "coadyuvar a los gastos públicos mediante el pago de impuestos" (A. N. C, 2000: Art. 133). Es decir, limita la obligación al pago de los tributos. Y más adelante prohíbe expresamente las "obligaciones tributarias" pagaderas en servicios personales (A. N. C, 2000: Art. 317).

¿Significaría esto entonces que la obligación de autoliquidar carece de cobertura constitucional? La prohibición constitucional es una norma antigua que solo buscaba evitar la imposición de servidumbres y no estaba orientada a impedir la colaboración ciudadana en el sostenimiento del Estado. El artículo 132 de la CRBV (A. N. C, 2000) exige un sistema eficiente para la recaudación de los tributos. Y solo un sistema que cuente con la activa colaboración del contribuyente y en general de la ciudadanía, relacionada con cada contribuyente, permite una recaudación cuyos costos no excedan los ingresos y que no sea excesivamente intrusivo sobre la libertad individual.

Si el Estado confía en el cumplimiento voluntario de los contribuyentes sin más, terminará en la quiebra. Todos, con excepción de los anarquistas, consideran necesario al 
Estado. Los neoliberales proclaman el Estado mínimo, no la anarquía. Los socialdemócratas proclaman el Estado intervencionista. Unos y otros coinciden en la necesidad de recurrir a impuestos para financiarlos, básicamente al menos. Pero, los primeros creen que los impuestos son excesivos y los segundos creen que los impuestos deben pagarlos otros. Por tanto, si los impuestos se pagan no es por el convencimiento de su necesidad sino bajo la amenaza de la sanción, del castigo. El Estado entonces, debe vigilar a los contribuyentes para asegurarse de que cumplen con sus obligaciones y que no intentan evadir el pago de impuestos. Obligación que por demás se limita a pagar estrictamente lo que la ley ordena. No menos pero tampoco más (Hand en Morgan, 1999: $3)$.

\section{La función inspectora}

El Estado tiene la obligación de hacer cumplir la ley, y un medio de hacerlo es a través de las inspecciones tributarias, éstas se traducen en: “la realización de actos jurídicos y operaciones sin una rígida secuencia temporal... con una exclusiva finalidad adquisitiva y de control sobre hechos y actos efectuados por particulares para adquirir elementos valorativos, de hecho y de derecho necesarios para adoptar un acto administrativo (Tenore, 1999: 9).

Se trata de una potestad pública, una facultad de obrar, limitada que sólo puede ser ejercida lícitamente en interés público, de fundamento constitucional o legal, de carácter general, que permite producir efectos jurídicos y frente a ella todos los contribuyentes se hallan en una situación pasiva de inercia (García de Enterria y Fernández, 1995: 32).

Esa potestad se hará concreta cuando la ley lo ordene o cuando la Administración en razón de una denuncia o por ś misma perciba indicios de defraudación que exijan la actuación inspectora. Así por ejemplo: cuando el enriquecimiento neto, en dos períodos consecutivos, sea inferior al $10 \%$ de los ingresos brutos de un contribuyente, el Seniat deberá realizar una inspección (A. N, 2001a: Art. 96). Los contribuyentes que gocen de exenciones, con cierta periodicidad, deberán ser inspeccionados ( $A$. N, 2001a: Art. 90). Los programas automáticos y aleatorios de fiscalización y los basados en signos exteriores de riqueza pueden resultar eficaces pero fuera de Venezuela, a las primeras se les ha llamado "inspecciones desde el infierno" y han sido prohibidas por ser excesivamente intrusivas (Morgan, 1999: 56). Pues no hay siquiera indicios que justifiquen someter a la persona a la presión que representa una inspección fiscal.

El fundamento legal de la potestad tributaria general esta en el Código Orgánico 
Tributario, que faculta a la Administración Tributaria para practicar fiscalizaciones, realizadas en su propia sede sobre la base de las declaraciones que acompañan la autoliquidación, exigir información a los contribuyentes, requerir la comparecencia de contribuyentes y terceros, recabar información de terceros, incluso de otros entes y órganos públicos (A. N, 2001b: Art. 137).

De manera general, la fiscalización tributaria procederá, además de los casos de autoliquidación, ya vistos supra, cuando se hayan otorgado devoluciones o recuperaciones de impuestos pagados en exceso o cobrados indebidamente, o finalmente cuando sea necesaria la determinación por la Administración por no haberse procedido a la autoliquidación por el contribuyente. (A. N, 2001b: Art. 177). El SENIAT deberá, de manera regular, verificar las autoliquidaciones y declaraciones, y cuando se observen indicios objetivos tales como no presentar libros, omitir registros o se alteren registros ( $A$. N, 2001b: Art. 132) deberá proceder a fiscalizar. Sin embargo, la Administración dado el carácter discrecional de la fiscalización, deberá valorar previamente si el costo en personal, tiempo y dinero de la propia Administración se verá compensado por lo recaudado. El proceso de fiscalización emplea recursos que no pueden ser utilizados en otro procedimiento por lo que debe realizarse un análisis costo beneficio. Sería irrazonable y por tanto ilegal (Congreso de la República, 1981: Art. 12), iniciar un procedimiento para el cobro de una deuda cuya declaratoria de incobrabilidad fuese procedente (A. N, 2001b:Art. 54).

Tomando conocimiento de los hechos, la Administración Tributaria dictará una providencia en la cual se especificará el sujeto pasivo, el tributo objeto del procedimiento identificando al funcionario responsable y se notificará al contribuyente, con lo cual quedará autorizado el funcionario para actuar (A. N, 2001b: Art. 178).

La fiscalización se podrá hacer en la sede de la Administración Tributaria (A. N, 2001b: Art. 180). En este caso precisamente se solicitará información a terceros que tengan relación con el contribuyente, quienes, según el artículo 124 del COT (A. N, 2001b), quedan obligados a suministrar la información que les sea requerida sin que se puedan amparar en el secreto bancario, ni el secreto profesional. Este deber a cargo del tercero le impone costos, puesto que deberá dedicar tiempo, dinero, y personal para ayudar al SENIAT a recaudar, en caso de que haya realmente evasión, los tributos que otro debe por lo cual habrá que fundamentarse jurídicamente.

El artículo 124 del COT (A. N, 2001b) exige proporcionar informaciones con carácter general o particular. El artículo 137 ejusdem (A. N, 2001b) se refiere a información de 
terceros relacionados con el hecho imponible. Pero, la norma peca de extrema generalidad, es vaga en exceso. Sólo es razonable exigir información con trascendencia tributaria, que derive de la relación económica con un tercero, que está siendo sometido a investigación (López, 1992: 52). Toda información que no tenga incidencia sobre la comprobación de un hecho imponible y la determinación tributaria, o sobre la comprobación de una infracción tributaria es irrelevante y no existe la obligación de proporcionarla.

Debe surgir con ocasión de una relación económica como con proveedores y compradores. O de una relación financiera como con los bancos. O profesionales como con los abogados o contadores que prestan servicios al contribuyente. Pero también de acuerdo con el artículo 127 del Código Orgánico Tributario (A. N, 2001b) la obligación recaería sobre los funcionarios públicos que en ejercicio de sus funciones privativas obtengan información de relevancia tributaria.

\section{El secreto profesional y el suministro de información}

El artículo 124 del COT (A. N, 2001b) sólo excluye del deber de suministrar información a los profesionales que no estén bajo relación de dependencia. El secreto profesional en el caso del abogado significa que: Cuando se busca consejo legal de cualquier clase de asesor legal de profesión, la comunicación relacionada con ese fin, hecha confidencialmente por el cliente, está a su instancia permanente protegido de revelación por sí mismo, o por el asesor, excepto que, se desista de la protección. (Wigmore en Gowdy, 1999: 697).

La ley de Abogados (Congreso de la República, 1966: Art. 1) y el Código de Ética (Federación de Abogados, 1985: Arts. 25 al 29) establecen la obligación del abogado de guardar secreto de todo lo revelado al pedírsele opinión, consejo o patrocinio. La razón de este derecho del cliente, y la obligación del abogado está en la necesidad del cliente de poder sin miedo a consecuencias dañosas para sus derechos o intereses, hablar abiertamente y sin ningún tipo de reticencia y poder obtener el consejo que se busca (López, 1992: 156). Y sólo se puede aconsejar debidamente si se conocen todos los hechos que el cliente conoce (Rice, 2000). La no garantía del secreto profesional se traduciría en indefensión, violatoria del artículo 49 CRBV (A. N. C, 2000).

Pero si hay relación de dependencia, la ley desconoce el secreto profesional. Es decir, la obligación del profesional desaparece si recibe un sueldo, instrucciones y ordenes del contribuyente. Por lo demás es de observarse que en algunos casos, el profesional deberá 
negar los datos no en razón del secreto profesional sino de la protección de la intimidad del cliente (López, 1992: 164), tal es el caso de los médicos.

El hecho de que no se permita alegar al dependiente el secreto profesional plantea la duda razonable de violación no sólo del secreto profesional, sino también del derecho a no confesar según el artículo 49 CRBV (A. N. C, 2000). La persona trasmite amparada en la garantía del secreto, la información al abogado o contador. Si el Estado tiene acceso a esa información, está obteniéndola, a todo efecto práctico, de la persona que tiene derecho a no reconocerse culpable. En definitiva se traduce en una violación al derecho a no autoinculparse.

\subsection{Información en razón de relaciones administrativas}

El Estado requiere información para el cumplimiento de sus fines. Si el Estado busca satisfacer necesidades colectivas concretas debe primero saber que existen, y cuán profundos son sus alcances. Por ejemplo: el Estado solicita, a través básicamente del censo, pero tambi én de encuestas, entrevistas y otros medios, información que le permite identificar los sectores necesitados de su acción. Esa información que es el insumo básico de un proceso de planificación, sólo es útil si es precisa, real, confiable, veraz. Para obtener la verdad el Estado garantiza el secreto estadístico y esa información no podrá ser utilizada sino es para el fin para el cual fue expresamente recolectada, luego no podrá ser suministrada a la Administración Tributaria (P. R, 2001b: Art. 11). Caso contrario, la reticencia de los particulares sería inevitable. El Código Orgánico Tributario reconoce el derecho del ciudadano a que la información obtenida con finalidades tributarias sea utilizada exclusivamente con ese fin (A. N, 2001b: Art. 126), pero incurriendo en una inconsistencia intrasistemática exige de los funcionarios suministrar información obtenida para cumplir otra función (A. N, 2001b: 124). El exigir o autorizar la comunicación de datos obtenidos por una autoridad que está en cumplimiento de sus funciones, atenta contra la eficacia con la cual se ordena actuar a la Administración en el texto constitucional (A. N. C, 2000: Art. 141). Y la eficacia no es un simple principio, es la exigencia fundamental de la legitimidad de un Estado. Un Estado que no puede cumplir los cometidos en razón de los cuales las personas renuncian a su libertad es un no Estado. No hay diferencia entre un Estado ineficaz y la anarquía.

\section{EI proyecto ROCA}

El desarrollo de la actividad económica requiere capital. La provisión de éste puede depender del sistema bancario o bien de la bolsa. En un caso o en otro, la existencia de 
costos de transacción (aquellos en que se incurre para descubrir oportunidades, celebrar un acuerdo o hacerlo cumplir) pueden impedir el funcionamiento del sistema. Los costos de transacción, también, derivan de la asimetría de la información, el banco, el ahorrista, el prestatario no poseen la información completa sobre las posibilidades de negocio. O si la tienen pueden no negociar por la incertidumbre sobre la calidad de la información, la incertidumbre se traduce en riesgo.

Asimismo, existen externalidades, costos que recaen sobre terceros y que no son asumidos internalizados por quien los produjo. El banco que realiza préstamos arriesgados puede luego recobrarse imponiendo los costos sobre otros préstamos o los ahorristas. Visto esto, el Estado puede justificar el actuar en orden a: La restricción intencional de la elección de las actividades de un sujeto y proviene de una entidad que no es parte directa ni esta involucrada en dicha actividad (Mitnick, 1989: 40).

Es lo que se llama regulación, y en el caso del sistema financiero la regulación se basa en la "precisión y disponibilidad de información" (Banco Mundial, 2002: 77) sobre la fundamentación económica de la actuación del banco. Es necesario controlar variables tales como: si se otorgan créditos a personas por motivos partidistas, o si se otorgan a quienes no presentan garantías adecuadas, bajo los efectos del riesgo moral resultado del tamaño del banco o la garantía de depósitos (Banco Mundial, 2002: 79). Y la información relativa a tales operaciones sólo la poseen los propios bancos. En el derecho comparado la regla en cuanto al deber de los bancos es el de comunicar la información sobre los clientes a las autoridades de control del sistema financiero. Así, en Francia donde no se puede oponer en secreto bancario al banco de Francia ni a la Comisión Bancaria (European Banking Federation, EBF, 2002: 12). En Alemania, las autoridades de regulación bancaria pueden acceder a la información de los clientes para la labor de supervisión o bien para determinar la solvencia de un cliente. En Italia, si los tribunales penales o la administración financiera solicitan la información no hay restricciones sobre el acceso (EBF, 2002: 13-17).

El proyecto ROCA o Sistema de Información Integral Automatizado de Bancos e Instituciones Financieras, se concibe entonces dentro de una tendencia amplia de no oponibilidad del secreto bancario a las autoridades de regulación del sector financiero. Y no pretende sustituir al Sistema de Información Central de Riesgos (S.I.C.R.I.). Todavía no se ha definido cuál debe ser la información que los bancos deben enviar (Sudeban, 2004). Pero debe limitase a la información patrimonial, no puede incluir la información personal que está unida a la información financiera, tales como identidad de los acreedores del cliente. $Y$ debe garantizarse que no será comunicada a otras autoridades, 
tales como las tributarias.

\subsection{El fundamento del deber de colaborar}

Fue estudiado ya el problema que surge de la formulación estrecha de la obligación de contribuir con los gastos públicos sólo a través del pago de tributos monetariamente, nunca en servicios. Esto obligó a forzar la inclusión del deber de autoliquidar en la obligación de solidaridad y en la exigencia de justicia del sistema tributario. Ahora un tercero, banco, comercio, pagador se encuentra obligado legalmente a distraer recursos de sus actividades propias y de una manera no compensada económicamente a colaborar con el Estado. Y esto, bien porque el tercero intenta evadir impuestos o bien simplemente porque el Estado sospecha que así es. Si el contribuyente realmente busca evadir impuestos, hay un inter és remoto en colaborar. Los impuestos que alguno evade se traducen a la larga en una mayor carga tributaria sobre aquellos que no pueden evadirlos. Pero eso ni es un incentivo real para la colaboración ni es un fundamento del deber. Debe buscarse de nuevo en el deber de solidaridad del artículo 132 de la CRBV (Asamblea Nacional Constituyente, 2000) el fundamento jurídico de la obligación del tercero. Por demás, cada persona al proveer la información esta ayudando al sostenimiento del Estado cuyos beneficios disfruta (Asamblea Nacional Constituyente, 2000: Art. 316). Asegurando la justa distribución de las cargas públicas.

\subsection{Subsidiaridad}

El contribuyente tiene una obligación constitucional y legal de proveer la información necesaria para la comprobación de su declaración. Si ésta falta la Administración procederá a la determinación de oficio. En el Código Orgánico Tributario de 1994 (Presidencia de la Republica, Art. 120) se estableció el carácter subsidiario de la misma. Sólo si el particular no proporcionaba los elementos de determinación procedía a actuar la Administración. Ahora es discrecional, lo cual sujeta el ejercicio de la potestad a los límites del artículo 12 de la Ley Orgánica de Procedimientos Administrativos (Congreso de la Republica, 1981) que exige la proporcionalidad de la acción administrativa. Esta se traduce en que: debe ser necesaria la actividad de la Administración. Debe utilizarse el medio menos gravoso para el particular. Y emplearse el medio con la menor intensidad posible (SandullI, 1998: 359). Y obviamente, es irrazonable imponerle la carga al tercero sin haber intentado obtener la información del propio contribuyente.

\section{Límites del deber de colaboración}


La competencia para inspeccionar y el deber de colaboración no son absolutos, tienen límites. El Código Orgánico Tributario no reconoce el secreto bancario como uno de ellos (A. N, 2001b: Art. 124). Pero cabe preguntarse si esta norma no colide con el derecho constitucional a la intimidad.

\section{a. El derecho a la intimidad}

Este derecho está consagrado expresamente por la CRBV (A. N. C, 2000: Art. 60) aunque se corresponde más con lo que en derecho comparado se conoce como privacy, pues: "la intimidad protege la esfera de la vida de la persona,- el domicilio donde se realiza su vida cotidiana, las comunicaciones en la que expresa sus sentimientos, por ejemplo - la privacidad constituye, un conjunto más amplio, más global de facetas de su personalidad, que aisladamente considerados- pueden carecer de significación intrínseca, pero que coherente enlazadas entre sí, arrojan como precipitando un retraso de la personalidad del individuo, que este tiene derecho a mantener reservado." (González Pérez y González Navarro, 2004: 1033).

Su fundamento último, está en la dignidad humana (A. N. C, 2000: Art. 3). La intimidad, el respeto a un ámbito que el particular tiene derecho a excluir de los demás, permite al individuo evitar ser objeto de humillaciones. Así como le permite autodeterminarse al permitirle su desarrollo sin la interferencia externa (Pérez Luño, 2003: 318).

Con ello se reconoce: "la significación de la naturaleza espiritual del hombre, de sus sentimientos y de su intelecto... ellos buscaban proteger (al ciudadano -agregado del autor-) en sus pensamientos, creencias, emociones y sensaciones (...) se confirió contra el gobierno el derecho de ser dejado solo -el más amplio de los derechos- el más valorado por los hombres civilizados. Para proteger ese derecho, toda intromisión injustificada del gobierno sobre la privacidad individual, debe considerarse una violación de la Constitución." (Brandeis en Supreme Court, 1928).

El derecho a la intimidad en consecuencia abarca básicamente las informaciones que se refieren a sí mismo y sus costumbres, a su estado de salud, hábitos y preferencias sexuales e ideas políticas. Estas informaciones en manos de otros pueden traducirse en discriminación, humillación o desprecio o incluso servir para la extorsión. Y la persona no tiene la obligación de enfrentar los perjuicios. En una sentencia de la antigua Corte Suprema de Justicia (1999) se negó la solicitud por parte de los accionantes seropositivos, de declaratoria de reserva del expediente y que sus nombres fueran testados. El argumento del Tribunal fue que el prejuicio contra los seropositivos es irracional, por lo 
que no deben esconderse. Obviamente, el acabar con el perjuicio no está en manos de los accionantes. Y nadie está obligado a la heroicidad. Ahora, basta con colocar el apellido y nombre de algunas personas y cualquier buscador de Internet mostrará en los resultados una sentencia en que la persona reconoce su seropositividad. Ante tal perspectiva muchos se abstendrán de intentar procesos en defensa de sus derechos.

\section{b. Intimidad y patrimonio}

Pero ¿el patrimonio forma parte de la intimidad?

En Venezuela, a partir de los años ochenta, el ascenso social fue duramente criticado. A quienes gracias a la educación, en especial programas como Fundayacucho, lograron sobresalir se les tachó como "nuevo ricos" y se les despreciaba. Reaccionarios y progresistas tenían un enemigo común, la clase media en ascenso. La riqueza obtenida por un medio distinto de la herencia, no podía ser sino el resultado de la corrupción. El tener dinero puede entonces ser una causa de rechazo social. Pero para otros sigue teniendo valor el dicho: tanto tienes, tanto vales. En definitiva la posesión o no de riquezas afecta la imagen que la sociedad tiene el individuo. Por lo que así como este tiene derecho a mantener fuera del conocimiento público su estado de salud, debe tener derecho a ocultar su estado de cuenta. Además, hay que agregar que la publicidad del patrimonio convierte a su titular en víctima potencial del hampa común y de la concusión.

Por otra parte, aún en el supuesto negado que el patrimonio no esté amparado por la intimidad, en las cuentas bancarias aparece reflejada información que sin lugar a dudas sí goza de tal protección. Allí figuran quiénes cobraron los cheques o emitieron un voucher de las tarjetas de crédito, tales como un siquiatra, la clínica del sueño, un motel. Con esa información es posible se forme una imagen de la persona que puede no corresponderse con la que desea mostrar.

\section{c. Límites del derecho a la intimidad}

Establecido, que en defensa de la intimidad patrimonial, o bien de los aspectos no materiales que se encuentran unidos a la información patrimonial, el secreto bancario forma parte de la intimidad personal, constitucionalmente caracterizada, ¿debe considerarse inconstitucional la previsión del artículo 124 del Código Orgánico Tributario (A. N, 2001b)? En principio sí. La no oponibilidad absoluta del secreto bancario viola la Constitución. Pero el derecho a la intimidad, como cualquier otro derecho, no es absoluto. Y puede ser limitado para asegurar un interés público (Warren y Brandeis, 1890: 66). La 
vigilancia del cumplimiento del deber de contribuir con las cargas públicas permite limitarlo. Esa incidencia sobre la intimidad debe estar guiada por el principio de proporcionalidad.

Por lo que debe limitarse a aquella información con trascendencia tributaria. Se flexibilizará el límite cuando se trate de obtener el soporte de aquellas operaciones que el particular utilizó para obtener desgravámenes del impuesto. Al hacerlo así, autorizó la comprobación de la veracidad de la operación. Pero la solicitud deberá referirse a la operaci ón específica y no a todas las operaciones.

De resto, sólo los movimientos de las cuentas relativas a ingresos tienen trascendencia tributaria. El monto total de egresos de la cuenta también puede indicar un nivel de riqueza superior al declarado. Pero respecto de estos únicamente puede obtenerse el monto total, o bien se debe individualizar la operación objeto de investigación so pena de violar la intimidad personal (Meneses, 2000: 222).

\subsection{Requisitos de la solicitud de información}

En el derecho comparado, es un requisito casi universal, la necesidad de un requerimiento individualizado (EBF, 2002: Anexo). Esto es necesario porque sólo así puede justificarse la incidencia sobre un derecho constitucional como lo es la intimidad (Meneses, 2000: 237). Únicamente de esta forma es posible determinar si la conducta del particular evidencia su intención de evadir el impuesto y por tanto se justifica la inspección. Es la única vía que permite al particular controlar que la información suministrada sea sólo aquella con trascendencia tributaria. Por demás sólo en el interior de un procedimiento puede realizarse la solicitud y no son posibles procedimientos colectivos.

\subsection{La protección de la información}

El Código Orgánico Tributario en orden a garantizar la colaboración de la actuación de la Administración establece una obligación de confidencialidad respecto de la información obtenida de terceros (A.N, 2001b: Arts. 126 y 132). La sanción por la violación de esta obligación está en el Código Penal (Comisión Nacional Legislativa, 2000: Art. 190) y es de prisión de 15 días a 3 meses.

\section{Conclusiones}


El Estado social de derecho requiere ingentes recursos. La ampliación de la base de contribuyentes y el recurso al impuesto sobre la renta traen complejidad a la recaudación y hacen a ésta intolerablemente invasiva.

El Estado, entonces, opta por un sistema de cumplimiento voluntario y posterior inspección y sanción. Lo que trae como consecuencia necesaria el deber a los particulares de proveer información. Este deber incluye a los terceros en relaciones económicas con el contribuyente. Pero el derecho a la intimidad que abarca al patrimonio y se expresa en el patrimonio bancario limita este deber. Debe entenderse entonces que el secreto bancario no es absoluto.

El secreto bancario protege la información en poder de las instituciones de crédito que puede tener, o no, carácter patrimonial en razón de la posibilidad de considerarse incluido en el derecho a reservarse la información, que aisladamente carece de significado pero puede arrojar un precipitado que la persona tiene derecho a conservar para sí o revelar. Esto es necesario pues esa información puede traer consecuencias negativas sobre el particular. Por demás, la duda sobre si la intimidad incluye los aspectos patrimoniales, se resuelve entendiendo que el secreto bancario es necesario para proteger informaciones personales anejas a las patrimoniales. Aquéllas sin duda están amparadas por el manto protector del derecho constitucional a la intimidad.

Ese derecho al secreto bancario puede limitarse además en virtud del deber de contribuir con el sostenimiento de las cargas públicas. La vigilancia de su cumplimiento exige que el Estado tenga acceso a la información en poder del banco, limitadamente. Pero sólo individualizada y exclusivamente a la información con trascendencia tributaria, básicamente los ingresos. De manera subsidiaria, motivado por la imposibilidad de obtener la información de otra manera. En definitiva, la limitación del derecho debe respetar su contenido esencial y debe ser razonable y necesaria. De manera que, previo requerimiento individualizado, motivado y limitado a la información sobre ingresos, puede exigirse su levantamiento.

\section{Referencias Bibliográficas}

1. Asamblea Nacional (2001a), Ley de Reforma Parcial de la Ley de Impuesto Sobre La Renta, Caracas. Venezuela.

2. Asamblea Nacional (2001b), Código Orgánico Tributario, Caracas. Venezuela. 
3. Asamblea Nacional Constituyente (2000), Constitución de la República Bolivariana de Venezuela, Caracas. Venezuela.

4. Banco Mundial (2002), World Development Report. Building Institution for the Markets, Washington D.C.

5. Comisión Legislativa Nacional (2000), Ley de Reforma Parcial del Código Penal, Caracas. Venezuela.

6. Congreso de la República (1981), Ley Orgánica de Procedimientos Administrativos. Caracas. Venezuela.

7. European Banking Federation (2002), Summary of National Legislation on Bunking Secrecy, http: //www.fbe.be/docs-fiscal.htm, 16-04-2004

9. Federación de Abogados de Venezuela (1985), Código de Ética, Venezuela.

10. Fernández, María José (1995), La Autoliquidación Tributaria, España, Marcial Pons, Instituto de Estudios Fiscales.

11. García de Enterria, Eduardo y Fernández, Tomás (1995). Curso de Derecho Administrativo, Tomo I, España Civitas.

12. González Pérez, Jesús y González Navarro, Francisco (2004), Comentarios a la Ley de Régimen Jurídico de las Administraciones Públicas y Procedimiento Administrativo Común. España Civitas.

13. Gowdy, Bryan. (1999), Should the Federal Government have an Attorney Client Privilege? Florida Law Review. Vol. 51. Estados Unidos University of Florida. Pp. 630687.

14. Harris, Marvin. (1985) ,Caníbales y Reyes. Madrid. Salvat.

15. Hume, David. (1740), Tratado de la Naturaleza Humana. Volumen III. Madrid Orbis. 1982.

16. López, Juan (1992), Los Deberes de Información Tributaria. España. Marcial Pons. Instituto de Estudios Fiscales. 
17. Meneses, Alfredo (2000), El Deber de Colaboración de las Entidades de Crédito ante los Requerimientos de Información de la Administración Tributaria, España, Civitas.

18. Mitnick, Barry (1989), La Economía Política de la Regulación, México, Fondo de Cultura Económica.

19. Morgan, Patricia (1999), Tax Procedure and Tax Fraud, Estados Unidos, West Group.

20. Pérez Luño, Antonio (2003), Derechos Humanos. Estado de Derecho y Constitución, España, Tecnos.

21. Presidencia de la República (1994), Decreto Ley de Reforma Parcial del Código Orgánico Tributario, Venezuela.

22. Presidente de la República (1999), Decreto con Rango y Fuerza de Ley de Simplificación de Trámites Administrativos. Venezuela.

23. Presidencia de la República (2001a), Decreto con Rango y Fuerza de Ley de Reforma de la Ley de Bancos y Otras Instituciones Financieras, Venezuela.

24. Presidencia de la República (2001b), Decreto con Rango y Fuerza de Ley de la Función Pública de Estadística. Venezuela

25. Rice, Paul (2000), Attorney Client Privilege .The Continuing Confusion about Attorney Communication. Drafts, Preexisting Document and the Source of the Fact. http://wcl.american.edu/pub/journals/lawrev.rice 19-02-2000.

26. Rodríguez, Corina (2004), Bancos Informaron al Seniat que no entregarán la información que solicita, en EI Nacional (13-04-04) Caracas, Venezuela.

27. Sandulli, Aldo (1998), La Proporzionalita dell'azione Amministrativa, Italia, Cedam.

28. Smith, Adam (1776), Investigación sobre la Naturaleza y Causas de la Riqueza de las Naciones. México. Fondo de Cultura Económica. 1982. 
29. Stigler, George (1970), Director's Law of Public Income Redistribution, en Chicago Studies in Political Economics, Estados Unidos, University of Chicago Press, 1988, pp. 106-115.

30. Sudeban (2004a), Proyecto ROCA. Información General, http://www.sedeban.gov.ve/sudeban/busqueda/contenido. secion.jsp?codigo=15204358. Fecha de consulta: 19-04-2004.

31. Sudeban (2004b), Suspendido plan piloto de Sudeban en Descifrado. http://www. Hisninewpress.com/descifrado/ hanrd/?id=183. Consultado, 19-04-2004 2004.

32. Supreme Court (1928), Dissenting Opinion Olmsteds vs. United States 277 US 438 (US SCT) en http://www2.law. cornell/edu/cgi.bin/ foloigci.ex/historic, 5-8-1999.

33. Tenore, Vito (1999), L' I spezione Amministrativa e il suo Procedimento, Italia. Giuffre Editore.

34. Warren, Samuel y Brandeis, Louis (1890), EI Derecho a la Intimidad, España, Civitas, 1995. Madrid. España. 